\title{
A polymorphism in the 3'-UTR of cyclooxygenase-2 and the risk of gastric cancer
}

\author{
TOMOYUKI SHIBATA, TOMIYASU ARISAWA, TOMOMITSU TAHARA, \\ ICHIRO HIRATA and HIROSHI NAKANO \\ Department of Gastroenterology, Fujita Health University, School of Medicine, Toyoake, Aichi 470-1192, Japan
}

Received February 6, 2008; Accepted March 21, 2008

\begin{abstract}
A polymorphism within the 3'-UTR 8473T $\rightarrow$ C of the cyclooxygenase-2 (COX-2) gene, which plays a role in gastrointestinal cancer development, has been associated with susceptibility to malignant disease. Here, we report on the interaction between the COX-2 3'-UTR $\mathrm{T} \rightarrow \mathrm{C}$ polymorphism and gastric cancer development. DNA from 121 Japanese patients with gastric cancer and 126 age-matched control patients was examined for the COX-2 polymorphism by PCRRFLP. Odds ratios and the $95 \%$ confidence interval (CI) were calculated. Homozygous carriage of the COX-2 8473C allele tended to be associated with an increased risk of gastric cancer compared to the $\mathrm{T}$ allele homozygotes of the subjects $(\mathrm{OR}=3.70 ; 95 \% \mathrm{CI}, 0.96-14.25)$. The CC allele was associated with a significant increased risk of diffuse-type gastric cancer $(\mathrm{OR}=5.29 ; 95 \% \mathrm{CI}, 1.18-23.70)$. These findings suggest that the COX-2 3'-UTR 8473T $\rightarrow$ C polymorphism could be used as a marker for genetic susceptibility to gastric cancer in Japanese populations.
\end{abstract}

\section{Introduction}

Gastric adenocarcinoma continues to be a considerable global health problem. Although its incidence and mortality rate have decreased over the last few decades, gastric cancer is second only to lung cancer as the leading cause of cancer death worldwide $(1,2)$. Helicobacter pylori $(H$. pylori) has been designated a causative pathogen for gastric carcinogenesis (3); however, only a small number of infected patients actually develop gastric cancer. This suggests that genetic factors may also play an important role in carcinogenesis of the stomach.

The cyclooxygenase-2 (COX-2) gene is a member of the prostaglandin synthase family of genes. Recent progress in the investigation of this gene has demonstrated that COX-2 is

Correspondence to: Dr Tomoyuki Shibata, Department of Gastroenterology, Fujita Health University School of Medicine, 1-98 Dengakugakubo, Kutsukake-cho, Toyoake, Aichi 470-1192, Japan E-mail: shibat03@fujita-hu.ac.jp

Key words: gastric cancer, cyclooxygenase-2, PCR, polymorphism a key regulator of inflammatory change and is associated with gastrointestinal cancer development (4-6). It has been suggested that the COX-2 8473T $\rightarrow$ C 3'-untranslated region (UTR) variant affects COX-2 mRNA levels (7), because this polymorphism is located in the post transcriptional regulatory region. The COX-2 polymorphism at the 8473 position has recently been associated with lung, breast and colorectal cancer (8-12). However, the association of this variant with gastric cancer risk has not been studied previously.

In this case-control study, we demonstrated the association between the risk of gastric cancer and the genetic polymorphism at position 8473 in the 3 '-UTR of the COX-2 gene using gastric biopsy samples.

\section{Materials and methods}

Patients and controls. The study population was comprised of patients who had received an upper gastrointestinal endoscopy at the Fujita Health University Hospital. A total of 121 Japanese patients (90 males and 31 females) diagnosed with primary gastric cancer participated in the study. Gastric cancer was histologically diagnosed at the division of pathology of the Fujita Health University Hospital and classified according to Lauren's classification (13). Information regarding cancer staging and anatomic location was obtained. A total of 126 age- and gender-matched patients ( 84 males and 42 females) who had undergone an upper gastrointestinal scope but did not have gastric cancer were evaluated as controls. Cases with collagen disease or inflammatory bowel disease, as well as those prescribed non-steroidal anti-inflammatory drugs, were excluded. The Ethical Committee of Fujita Health University, School of Medicine approved the study protocol. Written informed consent was obtained from all subjects.

DNA extraction. Gastric biopsy specimens were taken from non-cancerous mucosa in the antrum greater curvature of the stomach by means of the upper gastrointestinal endoscopy. Genomic DNA was then extracted from the samples using a proteinase K and DNA extraction kit (Qiagen, Valencia, CA).

Analysis of the COX-2 gene polymorphism. The genotype of the COX-2 polymorphism at position 8473 in the 3'-UTR was determined using PCR-based primer-introduced restriction analysis (PIRA) as previously described (8). Identification was performed after PCR-amplification using the following 
Table I. Subject characteristics.

\begin{tabular}{lccc}
\hline & GC & Controls & P-value \\
\hline No. & 121 & 126 & \\
Males/females & $90 / 31$ & $84 / 42$ & $\mathrm{NS}$ \\
Average age ( \pm SD) & $65.3 \pm 12.3$ & $63.0 \pm 12.4$ & $\mathrm{NS}$ \\
HP positive rate (\%) & 91.7 & 76.2 & $<0.05^{\mathrm{a}}$ \\
\hline $\begin{array}{l}\text { GC, gastric cancer; HP, H. pylori; NS, not significant. }{ }^{\mathrm{a} G C} \text { vs. Con- } \\
\text { trols, Mann-Whitney U test. }\end{array}$ &
\end{tabular}

primers: 5'-GTTTGAAATTTTAAAGTACTTTTGAT-3' and 5'-TTTCAAATTATTGTTTCATTGC-3'. PCR was carried out in a volume of $20 \mu \mathrm{l}$ containing $0.1 \mu \mathrm{g}$ of genomic DNA. The DNA was denatured at $96^{\circ} \mathrm{C}$ for 5 min followed by 35 cycles at $96^{\circ} \mathrm{C}$ for $30 \mathrm{sec}, 53^{\circ} \mathrm{C}$ for $40 \mathrm{sec}$ and $72^{\circ} \mathrm{C}$ for $45 \mathrm{sec}$, with a final extension at $72^{\circ} \mathrm{C}$ for $10 \mathrm{~min}$. The PCR reaction was performed using EX Taq (Takara Bio Inc., Shiga, Japan). The amplified PCR products were digested overnight with $5 \mathrm{U}$ of BclI (New England BioLabs Inc., Beverly, MA, USA) at $50^{\circ} \mathrm{C}$. Subsequently, the digested products were analyzed on $10 \%$ polyacrylamide gels. These gels were stained with silver staining kit (Atto Corp., Tokyo, Japan), and the genotypes and alleles were determined by analyses of the different bands as described previously (8). The presence of a $B c l$ I site was indicated by the cleavage of the $147 \mathrm{bp}$ amplified product to yield fragments of 124 and $23 \mathrm{bp}$.

Detection of Helicobacter pylori. H. pylori positivity was determined by microscopic examination, the rapid urease test or serum anti-HP antibody titer. Infection was diagnosed when at least one of these tests was positive.

Statistical analysis. The clinical characteristics of patients with or without gastric cancer were compared using the MannWhitney U test. Logistic-regression analysis was performed to find the odds ratio (OR) and $95 \%$ confidence interval (CI) for gastric cancer of the genetic polymorphism, with adjustment for age, sex and $H$. pylori infection status. A probability value of $<0.05$ was considered statistically significant.

\section{Results}

Subject characteristics. The characteristics of the patients and control subjects who participated in this study are summarized in Table I. There were no significant differences between the case and control groups in terms of age or gender distribution. The infection rate of $H$. pylori was higher in the gastric cancer patients $(\mathrm{p}<0.05)$.

Distribution of COX-2 genotypes. Table II shows the genotype frequencies of COX-2 in patients with gastric cancer and in the control group. A polymorphism at position 8473 of COX-2 was identified in all 247 subjects. Of all the cases and controls, homozygous carriage of the COX-2 $8473 \mathrm{C}$ allele tended to
Table II. The COX-2 polymorphism and the risk of gastric cancer.

\begin{tabular}{|c|c|c|c|c|}
\hline Genotypes & $\begin{array}{c}\text { No. GC } \\
\text { patients } \\
(\%)\end{array}$ & $\begin{array}{c}\text { No. } \\
\text { controls } \\
(\%)\end{array}$ & OR $(95 \% \mathrm{CI})$ & P-value \\
\hline $\mathrm{T} / \mathrm{T}$ & $69(57.0)$ & $69(54.8)$ & Reference & \\
\hline $\mathrm{T} / \mathrm{C}$ & $41(33.9)$ & $54(42.9)$ & $0.78 \quad(0.46-1.35)$ & 0.15 \\
\hline $\mathrm{C} / \mathrm{C}$ & $11(9.1)$ & $3 \quad(2.4)$ & $3.70(0.96-14.25)$ & 0.07 \\
\hline
\end{tabular}

GC, gastric cancer; CI, confident interval.

be associated with an increased risk of gastric cancer when compared to the $\mathrm{T}$ allele homozygotes of the controls (OR=3.70; 95\% CI, 0.96-14.25) (Table II).

For further investigation, the association between the COX-2 polymorphism and the clinicopathologic features of gastric cancer, tumor location, stage, and Lauren's histological classification were included in a stratified analysis.

Among these clinicopathologic features, we found that a CC homozygote polymorphism was associated with an increased risk of diffuse-type gastric cancer $(\mathrm{OR}=5.29$; 95\% CI, 1.18-23.70) (Table III). No statistical differences between the $H$. pylori positivity rates of intestinal and diffusetype gastric cancer were found.

The main endoscopic findings in the control group were: gastric ulcer in 42 patients $(33.3 \%)$, duodenal ulcer in 16 $(12.7 \%)$, gastric and duodenal ulcer in $2(1.6 \%)$ and gastritis in $66(52.4 \%)$. No significant genotype differences among the patients with gastric ulcer, duodenal ulcer and gastritis were found in the controls (data not shown).

\section{Discussion}

In the present study, we found that the $8473 \mathrm{~T} \rightarrow \mathrm{C}$ polymorphism of the COX-2 gene tended to be associated with an increased risk of gastric cancer in a Japanese population. In particular, the frequency of the CC homozygote genotype of this polymorphism was significantly higher in patients with diffuse-type gastric cancer than in the controls.

COX-2 may affect the process of inflammation in carcinogenesis. It is expressed in the stomach and plays diverse roles in cases of mucosal injury by inducing prostaglandins in the stomach (14). COX-2 also plays an important role in the development of various kinds of cancer (15-18); indeed, the correlation between enhanced expression of COX-2 and gastric cancer has been previously reported (19-22). Moreover, COX-2 expression has been detected in pre-malignant lesions $(21,23,24)$. These reports provide strong evidence that COX-2 affects gastric cancer development.

Several studies have investigated the association between the COX-2 8473T $\rightarrow$ C polymorphism and the risk of several types of cancer $(8-12,25)$. Our data are in accordance with three previous studies, which showed a similar association with the CC genotype in lung (10), colorectal (12) and breast 
Table III. Association between the COX-2 polymorphism and tumor location, staging and Lauren's classification.

\begin{tabular}{|c|c|c|c|c|c|}
\hline \multirow[b]{2}{*}{ Variables (No.) } & \multicolumn{3}{|c|}{ Genotype } & \multirow{2}{*}{$\begin{array}{l}\text { C/C vs. T/T } \\
\text { OR }(95 \% \mathrm{CI})\end{array}$} & \multirow[b]{2}{*}{ P-value } \\
\hline & $\mathrm{T} / \mathrm{T}$ & $\mathrm{T} / \mathrm{C}$ & $\mathrm{C} / \mathrm{C}$ & & \\
\hline Patients without GC (126) & 69 & 54 & 3 & Reference & \\
\hline \multicolumn{6}{|l|}{ Tumor location } \\
\hline Cardia (5) & 1 & 2 & 2 & ND & \\
\hline Non-cardia (116) & 68 & 39 & 9 & $2.81(0.69-11.48)$ & 0.150 \\
\hline Upper third (3) & 3 & 0 & 0 & ND & \\
\hline Middle third (69) & 39 & 26 & 4 & $2.45(0.48-12.60)$ & 0.284 \\
\hline Lower third (44) & 26 & 13 & 5 & $5.08(0.86-30.21)$ & 0.074 \\
\hline \multicolumn{6}{|l|}{ Staging } \\
\hline Early (53) & 31 & 18 & 4 & $3.40(0.64-18.12)$ & 0.153 \\
\hline Advanced (68) & 38 & 23 & 7 & $3.24(0.73-14.31)$ & 0.121 \\
\hline \multicolumn{6}{|l|}{ Lauren's classification } \\
\hline Intestinal-type (62) & 39 & 19 & 4 & $2.00(0.38-10.67)$ & 0.415 \\
\hline Diffuse-type (53) & 27 & 20 & 6 & $5.29(1.18-23.70)$ & 0.030 \\
\hline Mixed (6) & 3 & 2 & 1 & ND & \\
\hline
\end{tabular}

All data are adjusted for sex, age and H.pylori infection status. GC, gastric cancer; ND, not determined.

cancer (11). Three other studies described a protective role for the CC genotype in lung cancer $(8,9,25)$. The reason for this discrepancy is currently unclear; however, it may be due to etiologic differences among these tumors. Another possibility for the discrepancies between this single nucleotide polymorphism (SNP) and carcinogenesis in different tumors is ethnic diversity. The varied genetic background of the study population should be taken into consideration because, in linkage disequilibrium with the COX-2 8473T $\rightarrow$ C polymorphism, other linked polymorphisms that have causal effects on the susceptibility to gastric cancer may present differently in different ethnic groups.

In lung cancer studies, there have been reports which show that the COX-2 polymorphism is associated with tumor histology. The results of our study indicate that the $\mathrm{CC}$ genotype is susceptible to diffuse-type gastric cancer, but do not suggest an association between the COX-2 SNP and intestinal-type gastric cancer. While the reasons for the observed histologyassociated differences in the risk created by the COX-2 polymorphism remain to be clarified, this result is attributable to differences in the pathways of carcinogenesis between the various histological types of gastric cancer. $H$. pylori is a very powerful pathogenic factor in the stomach, and intestinal-type gastric cancer is strongly related to multi-step carcinogenesis of the chronic inflammation (gastritis)-metaplasia-carcinoma sequence (26). Therefore, the susceptibility of the CC genotype of COX-2 to cancer may have more influence on the diffuse type than on the intestinal type of gastric cancer development. It is also possible that the $8473 \mathrm{~T} \rightarrow \mathrm{C}$ polymorphism in the COX-2 gene stabilizes COX-2 mRNA, resulting in differential COX-2 expression.
In the process of carcinogenesis, COX-2 can influence tumor invasion or metastasis (27-29). Thus, the COX-2 $8473 \mathrm{~T} \rightarrow \mathrm{C}$ polymorphism may affect the progression of tumor growth. In the present study, however, this polymorphism was not associated with the stage of gastric cancer.

In conclusion, these findings suggest that the COX-2 3'-UTR $8473 \mathrm{~T} \rightarrow \mathrm{C}$ polymorphism could be used as a marker for genetic susceptibility to gastric cancer in a Japanese population, particularly in diffuse-type gastric cancer cases. Larger studies are needed to confirm the influence of this gene on gastric carcinogenesis in Japanese populations and in an ethnically diverse population.

\section{Acknowledgements}

We thank all the medical staff of our endoscopy unit at the Fujita Health University Hospital for taking samples.

\section{References}

1. Murray CJ and Lopez AD: Global mortality, disability, and the contribution of risk factors: Global Burden of Disease Study. Lancet 349: 1436-1442, 1997.

2. Parkin DM, Bray F, Ferlay J and Pisani P: Global cancer statistics, 2002. CA Cancer J Clin 55: 74-108, 2005.

3. IARC Working Group on the Evaluation of Carcinogenic Risks to Humans: Schistosomes, liver flukes and Helicobacter pylori. IARC Monogr Eval Carcinog Risks Hum 61: 1-241, 1994.

4. Wang D, Mann JR and DuBois RN: The role of prostaglandins and other eicosanoids in the gastrointestinal tract. Gastroenterology 128: 1445-1461, 2005.

5. McAdam BF, Mardini IA, Habib A, et al: Effect of regulated expression of human cyclooxygenase isoforms on eicosanoid and isoeicosanoid production in inflammation. J Clin Invest 105: 1473-1482, 2000. 
6. Uefuji K, Ichikura T and Mochizuki H: Cyclooxygenase-2 expression is related to prostaglandin biosynthesis and angiogenesis in human gastric cancer. Clin Cancer Res 6: 135-138, 2000.

7. Cok SJ and Morrison AR: The 3'-untranslated region of murine cyclooxygenase- 2 contains multiple regulatory elements that alter message stability and translational efficiency. J Biol Chem 276: 23179-23185, 2001.

8. Hu Z, Miao X, Ma H, et al: A common polymorphism in the 3'UTR of cyclooxygenase 2/prostaglandin synthase 2 gene and risk of lung cancer in a Chinese population. Lung Cancer 48: $11-17,2005$.

9. Park JM, Choi JE, Chae MH, et al: Relationship between cyclooxygenase $8473 \mathrm{~T}>\mathrm{C}$ polymorphism and the risk of lung cancer: a case-control study. BMC Cancer 6: 70, 2006.

10. Campa D, Zienolddiny S, Maggini V, Skaug V, Haugen A and Canzian F: Association of a common polymorphism in the cyclooxygenase 2 gene with risk of non-small cell lung cancer. Carcinogenesis 25: 229-235, 2004.

11. Langsenlehner U, Yazdani-Biuki B, Eder T, et al: The cyclooxygenase-2 (PTGS2) 8473T $>$ C polymorphism is associated with breast cancer risk. Clin Cancer Res 12: 1392-1394, 2006.

12. Cox DG, Pontes C, Guino E, et al: Polymorphisms in prostaglandin synthase 2/cyclooxygenase 2 (PTGS2/COX2) and risk of colorectal cancer. Br J Cancer 91: 339-343, 2004.

13. Lauren P: The two histological main types of gastric carcinoma: diffuse and so-called intestinal-type carcinom: an attempt at a histo-clinical classification. Acta Pathol Microbiol Scand 64: 31-49, 1965.

14. Peskar BM, Maricic N, Gretzera B, Schuligoi R and Schmassmann A: Role of cyclooxygenase-2 in gastric mucosal defense. Life Sci 69: 2993-3003, 2001.

15. Zhi H, Zhang J, Hu G, et al: The deregulation of arachidonic acid metabolism-related genes in human esophageal squamous cell carcinoma. Int J Cancer 106: 327-333, 2003.

16. Shamma A, Yamamoto H, Doki Y, et al: Up-regulation of cyclooxygenase-2 in squamous carcinogenesis of the esophagus. Clin Cancer Res 6: 1229-1238, 2000.

17. Romano M and Claria J: Cyclooxygenase-2 and 5-lipoxygenase converging functions on cell proliferation and tumor angio-genesis: implications for cancer therapy. FASEB J 17: 1986-1995, 2003.
18. Zimmermann KC, Sarbia M, Weber AA, Borchard F, Gabbert HE and Schror K: Cyclooxygenase-2 expression in human esophageal carcinoma. Cancer Res 59: 198-204, 1999.

19. Li HX, Chang XM, Song ZJ and He SX: Correlation between expression of cyclooxygenase- 2 and angiogenesis in human gastric adenocarcinoma. World J Gastroenterol 9: 674-677, 2003.

20. Chen XL, Su BS, Sun RQ, Zhang J and Wang YL: Relationship between expression and distribution of cyclooxygenase-2 and bcl-2 in human gastric adenocarcinoma. World J Gastroenterol 11: 1228-1231, 2005.

21. Saukkonen K, Rintahaka J, Sivula A, et al: Cyclooxygenase-2 and gastric carcinogenesis. APMIS 111: 915-925, 2003.

22. Van der Woude CJ, Kleibeuker JH, Tiebosch AT, et al: Diffuse and intestinal type gastric carcinomas differ in their expression of apoptosis related proteins. J Clin Pathol 56: 699-702, 2003.

23. Honjo S, Kase S, Osaki M, Ardyanto TD, Kaibara N and Ito $\mathrm{H}$ : Cyclooxygenase- 2 expression in human gastric tubular adenomas and carcinomas; correlation with intratumoral microvessel density and apoptotic index. Anticancer Res 24: 1439-1444, 2004.

24. Yamagata R, Shimoyama T, Fukuda S, Yoshimura T, Tanaka M and Munakata A: Cyclooxygenase-2 expression is increased in early intestinal-type gastric cancer and gastric mucosa with intestinal metaplasia. Eur J Gastroenterol Hepatol 14: 359-363, 2002.

25. Sørensen M, Autrup H, Tjønneland A, Overvad K, RaaschouNielsen O: A genetic polymorphism in prostaglandin synthase 2 $(8473, T \rightarrow C)$ and the risk of lung cancer. Cancer Lett 226: 49-54, 2005.

26. Correa P: Human gastric carcinogenesis: a multistep and multifactorial process - First American Cancer Society Award Lecture on Cancer Epidemiology and Prevention. Cancer Res 52: 6735-6740, 1992

27. Tsujii $\mathrm{M}$ and DuBois RN: Alterations in cellular adhesion and apoptosis in epithelial cells overexpressing prostaglandin endoperoxide synthase 2. Cell 83: 493-501, 1995.

28. Tsujii M, Kawano S, Tsuji S, Sawaoka H, Hori M and DuBois RN: Cyclooxygenase regulates angiogenesis induced by colon cancer cells. Cell 93: 705-716, 1998 .

29. Sheng H, Shao J, Washington MK and DuBois RN: Prostaglandin E2 increases growth and motility of colorectal carcinoma cells. J Biol Chem 276: 18075-18081, 2001. 